\title{
SNPs as Co-morbid Factors for Drug Abuse and Ischemic Heart Disease
}

\section{Mohammad Al-Haggar*}

Pediatrics and Genetics, Mansoura University Children's Hospital (MUCH), 35516 Mansoura, Egypt

\begin{abstract}
Drug abuse is a major health and social problem that may be associated with morbidity and mortality. It is considered by many societies as an antisocial or even criminal behavior. Susceptibility to addiction is multifactorial with complex genetic basis characterized by phenotypic and genetic heterogeneity. Candidate genes are those concerned with action and metabolism of abused drug or those that encode neurotransmitter systems. Comorbidity means the concomitance or sequential development of two disorders in one cohort. High prevalence of comorbidities does not mean that one condition caused the other, even if one appeared first. Neurocardiac involvement may be in the form of the heart's effects on the brain as in embolic stroke as a sequel of cardiac disease, the brain's effects on the heart as in neurogenic heart disease, and neurocardiac syndromes like Friedreich's ataxia. Recently, increasing evidences suggest genetic and epigenetic factors as a cause of comorbidity. Single nucleotide polymorphisms (SNPs) is the most interesting risk factor that could explain the personal variation in disease susceptibility especially the multifactorial comorbid disorders. In this article, we will review the role SNPs as a risk factor for the comorbidity of drug abuse and ischemic heart disease.
\end{abstract}

Keywords: Substance abuse; Ischemicheart; SNPs

\section{Introduction}

Drug abuse is a major concern that impacts all levels of society [1]. Generally, drug abuse is considered by many societies, an antisocial or even criminal behavior. Drug abuse is a major health and social issue for its morbidity and mortality, individual and society cost, violence and legal problems involvement. It is widely known that dependence on drugs of abuse is moderately to strongly heritable but, the susceptibility to addiction has a complex genetic basis characterized by phenotypic and genetic heterogeneity. Candidate genes are both specific genes, related to action and metabolism of drug of abuse, and non-specific genes that encode neurotransmitter systems that could influence the biological activity of the drug [2].

When two disorders or illnesses occur simultaneously in the same person, they are called comorbid. Surveys show that drug abuse and other mental illnesses are often comorbid. Six out of ten people with a substance use disorder also suffer from another form of mental illness. But the high prevalence of these comorbidities does not mean that one condition caused the other, even if one appeared first. In fact, there are at least three scenarios that should be considered; (1) drug abuse can cause a mental illness,(2) mental illness can lead to drug abuse, and (3) drug abuse and mental disorders are both caused by other common risk factors. In reality, all three scenarios can contribute, in varying degrees, to the establishment of specific comorbid mental disorders and addiction [3]. Although a variety of diseases commonly co-occur with drug abuse and addiction (e.g. HIV, hepatitis C, cancer, cardiovascular disease), most researches in this era focus only on the comorbidity of drug use disorders and other mental illnesses [3]. Neurocardiology has many dimensions and can be divided into three major categories: the heart's eff ects on the brain e.g. cardiac source embolic stroke, the brain's effects on the heart e.g. neurogenic heart disease, and neurocardiac syndromes e.g. Friedreich's disease [4].

In recent years, increasing evidences suggest that genetic and epigenetic factors could be involved in disease comorbidity. Given the central role of the genome and proteome in biology and pathobiology, it is safe to predict that misregulation of specific gene(s) and gene expression defects could influence the disease state and hence play a role in co-morbid disorders. Genes and Gene expression products are essential for the development and function of the brain and heart. DNA, SNPs, polymorphisms and changes in miRNA expression profiles leading to an increased risk for developing neurodegenerative disorders as well as heart failure [5]. Previous researches have demonstrated genetic and environmental influences on drug use disorders and cardiovascular risks separately, but there are less known about how these factors may influence the comorbidity, many studies are currently focusing on the role SNPs as risk factor.

In this article, we are review the role SNPs as a risk factor for the comorbidity of drug abuse and ischemic heart disease whatever who comes first.

\section{Biological components of substance abuse}

Drug/substance abuse and dependence are complex phenomena that defy simple explanation or description. The abusive use of addictive drugs is a medical and social problem as old as recorded human history. Ancient references to drug abuse may be found in the oral and written traditions of virtually all ethnic and cultural groups on the planet [6]. One of the most striking features of drug addiction is how few chemicals are subject to abuse. Among all congeners of all known chemicals, approximately 30,000,000 chemical substances, yet, only approximately 100 (including nicotine, ethanol, psychostimulants, opiates, barbiturates, benzodiazepines and cannabinoids) are addictive which is a stunningly small subset of the overall chemicals [7]. Many contributing factors including the actions and effects the drug could underlie the substance abuse and dependence. In order to understand substance abuse disorder one must first understand how drugs work in the brain, why certain drugs have the potential for abuse, and what, if any, biological differences exist among individuals in their susceptibility to abuse drugs [8].

The earlier onset of drug intake is associated with greater likelihood of development of substance use problems. However, there is debate about whether early onset uniquely affects brain development in such a way as to promote pathological behavior or whether the same genetic and environmental factors that make an individual likely to develop drug problems also make them likely to initiate early [9]. In the U.K. and North America, the understanding of addiction has been dominated by

*Corresponding author: Prof. Mohammad Al-Haggar, Pediatrics and Genetics, Mansoura University Children's Hospital (MUCH), 35516 Mansoura, Egypt Tel: +20-50-2310661/+2-011117-15350; Fax: +20-50-2234092; E-mail: m.alhaggar@yahoo.co.uk

Received January 20, 2014; Accepted February 06, 2014; Published February 10,2014

Citation: Al-Haggar M (2014) SNPs as Co-morbid Factors for Drug Abuse and Ischemic Heart Disease. Gene Technology 3: 107. doi: 10.4172/23296682.1000107

Copyright: (c) 2014 Al-Haggar M. This is an open-access article distributed under the terms of the Creative Commons Attribution License, which permits unrestricted use, distribution, and reproduction in any medium, provided the original author and source are credited. 
the disease theory and the social learning theory; implications of the disease theory depend on the notion that addiction is caused by some irreversible deficiency or pathology and that treatment is, therefore, primarily a medical concern. Certain conclusions inevitably follow from such a premise: (1) abstinence is the only treatment goal, (2) loss of control is the hallmark feature, (3) patients are not responsible for their illness, (4) therapists tend to be medical practitioners, and, finally, (5) community-based prevention will be ineffective [10]

There are 10 markers of substance dependence that translate the biopsychosocial status of substance abuser; 1) Preoccupation with drinking or taking drugs, 2) Salience of substance use behavior, 3) Compulsion to start using alcohol or drugs, 4) Planning alcohol- or drugrelated behaviors, 5) Maximizing the substance effect, 6) Narrowing of substance use repertoire, 7) Compulsion to continue using alcohol and drugs, 8) Primacy of psychoactive effect, 9) Maintaining a constant state (of intoxication), 10) Expectations of need for substance use. Two biological factors contribute to substance abuse and addiction: the effects drugs of abuse exert on the individual, and the biological status of the individual taking drugs. The former relates to the acute mechanisms of abused drug action in the brain and the long-term effects on chronic exposure. The latter pertains to an individual's biological constitution, most importantly the presence of inherited characteristics, which affects that person's response e.g. on areas of brain that mediate feelings of pleasure and reward. Ability of acute administration of the drug to the affected areas of brain that mediates the feelings of pleasure and reward is called brain reward systems. Reinforcement will compulse?? The person's behavior directed toward drug seeking.

Addictive drugs of different classes act on this three-neuron, inseries brain reward neural circuit at different points to activate the circuit and produce the drug-induced high. Barbiturates, benzodiazepines, cannabinoids, ethanol, nicotine and opiates act on synapses associated with the ventral tegmental area. Amphetamines, cannabinoids, cocaine, opiates and dissociative anesthetics such as ketamine and phencyclidine act on synapses associated with the nucleus accumbens [11]. Furthermore, the rewarding properties of psychostimulant drugs such as cocaine and amphetamines are due to a direct increase in the activity of the neurotransmitter dopamine in the mesocorticolimbic dopamine pathway. Opiates, on the other hand, indirectly stimulate dopamine activity by activating other neurotransmitter pathways, which in turn increase dopamine activity in the mesocorticolimbic pathway [6].

Chronic, long-term use can cause either permanent changes in the brain or alterations that may take hours, days, months, even years to reverse on drug cessation. These changes are adaptive responses related to the pharmacological action of a given drug that occur in the brain to counter the immediate effects of a drug. Dependence refers to a psychological and/or physical "need" for the drug; psychological dependence is an attribute of all drugs of abuse and centers on the user feeling that he or she needs the drug to reach a maximum level of functioning or well-being. This is a subjective concept that is difficult to quantify and, thus, is of limited clinical use. Physical dependence indicates that the body has adapted physiologically to the chronic use of the substance, with the development of tolerance or, when the drug is stopped, of withdrawal symptoms [12]. Tolerance to drug develops after chronic use leading to increased dosage to produce an originally effect, it is not restricted to elicit drugs and is not an all-ornone phenomenon, moreover cross tolerance to other drugs could occur. Abrupt withdrawal of this drug could results in withdrawal syndrome which is characterized by a series of signs and symptoms that are opposite to those of the acute effects of the drug; the cycle of addiction is positively reinforced by euphoria and negatively reinforced by withdrawal, craving and hedonic dysregulation [13].

\section{Genetic components of substance abuse}

The abuse liability of a drug is a measure of the likelihood that its use will result in drug dependence. Many factors ultimately play a role in an individual's drug-taking behavior; nevertheless, the abuse potential of a drug is related to its intrinsic rewarding properties and/ or the neuroadaptive responses that result from its prolonged use. Pharmacological drug criteria e.g. reinforcing effect, tolerance, and physical dependence are drug-related factors; reinforcing effect is essential for significant abuse potential, whereas tolerance and physical dependence are not absolutely required [14]. Liability is a measure for the role genetic factor in multifactorial traits which is sometimes termed as heritability. There is no natural clear-cut gap between the norm and pathology [15]. For instance, while the essence of addiction is considered to be compulsive drug seeking and use [16], the diagnosis of substance dependence is defined as the presence of any three or more of the seven symptoms, such as tolerance or taking substance often in larger amounts than intended. None of the symptoms are necessary or sufficient for the diagnosis, which makes the definition of the threshold even more uncertain. This uncertainty is one of the reasons making these disorders heterogeneous. Abuse liability is justified by the well documented high comorbidity of dependence on different substances often with opposite pharmacological effects [17], consistent pattern of staging in involvement with different drugs and the development of abuse [18], cross-tolerance and cross dependence on different substances, and common mechanisms underlying rewarding effects of drugs [19].

Moreover, familial aggregation of drug abuse [20], significant genetic correlations between genetic components of phenotypic variance, and/or co-transmission have been shown between liabilities to alcohol and drug use disorders [21], and substance use and smoking [22].

Variation in the liability is expressed as sub-threshold (nonaffected) phenotypes and supra-threshold (affected) phenotypes which is the population variation for the liability to substance abuse rather than an individual phenotype, in other words, the relative risk for substance abuse [15].

\section{Etiological Models of drug abuse and dependence}

Certainly, drug abuse is a multifactorial biopsychosocial problem; that is, the pathways to the problem of drug abuse are complex and cannot be explained by simple cause-and-effect models. Researchers have provided evidence for numerous predictors of drug use and misuse e.g. genetics, brain systems and structures, and cognitive processes. Increasingly, researchers have moved toward more "complex, dynamic, multidimensional, level/phase structured, nonlinear, and bounded e.g. culture, time, place, age, gender, and ethnicity. Consequently, several different integrated substantive models of substance abuse have been developed [23].

Vulnerability to drug abuse is a complex trait with three factors have been defined for its development; genetic factors, diverse environmental factors, and predicted drug-induced effects on gene expression; mRNA and peptide levels, proteins and neurochemistry, neural networks, physiology, and behavior [24,25].

Large body of evidence from family, adoption and twin studies, support strong genetic base of dependence which demonstrate substantial heritability $[15,24,26-29]$. Twin data converge on a common theme: drug abuse vulnerability has overall genetic components that explain $40-60 \%$ of the overall vulnerability $[24,28,30]$. To date, up to $70 \%$ of the risk for addictive behaviors can be attributed to heritable 
influences (alcohol: 50\%, cocaine 60\%, and opiates 70\%) [31], with four to eight folds increase in the risk of developing an addictive behavior if a first-degree relative has a substance abuse disorder [32,33]. Differences in concordance between genetically identical and fraternal twins also support heritability for vulnerability to addictions $[28,34]$. Family studies clearly document that first degree relative (e.g. sibs) of addicts display greater risk for developing substance dependence than more distant relatives $[20,26,28,34,35]$. Adoption studies consistently find greater similarities between substance abuse phenotypes with biological relatives than with adoptive family members [36]. Twin data also support the idea that the environmental influences on addiction vulnerability that are not shared among members of twin pairs are much larger than those that are shared by members of twin pairs [24]. Many environmental influences on human addiction vulnerability are thus likely to come from outside of the family environment [24,34]. The evidence suggests that no single variant accounts for a major portion of this risk, but the variations in many genes each contribute a small amount [29].

Many groups of researchers have hypothesized that dependence may be influenced by multiple polymorphisms of multiple genes. Whether vulnerability to drug abuse is enhanced or reduced by a general set of genetic variables, and, also whether there is a specific subset of polymorphisms for each drug of abuse or a combination of these has not yet been fully elucidated. Various combinations of genes with sets of different specific alleles, the frequency of which varies across ethnic/ cultural groups, may influence vulnerability to or protection from developing drug addiction [25].

An important issue in the investigation of vulnerability to drug abuse is whether there is a specific vulnerability for a single drug (such as cocaine), or a set of drugs (such as stimulants), or psychoactive substances in general. Glantz suggested that, at least for some abusers, the particular drug abused is almost incidental; it is the effect that motivates the individual. Abusers may use different drugs in different fashions to try to obtain the desired effect [37]. In criticizing the disease models of substance abuse because they imply that each type of addiction has a specific etiology, Tarter and Mezzich, concluded that "there is no definitive evidence indicating that individuals who habitually and preferentially use one substance are fundamentally different from those who use another [38]. A generalized behavioral deposition, or risk, is supposed by the following observations: (1) individuals who terminate abuse of one substance often initiate use of another; (2) no vulnerability factors have been identified that indicate risk for one particular substance; and (3) there is little evidence that abuse of any drug, "breeds true" within an particular family. Molecular, behavioral, and cellular research have elucidated central nervous system pathways that affect responses to ethanol, stimulants, opiates, and marijuana, and suggest unique as well as shared mechanisms of sensitivity, neuroadaptations and rewards [26].

The most common and best understood genetic effect occurs at the level of a change to a single nucleotide in a gene (SNP; single nucleotide polymorphism). There is growing evidence that SNPs have the potential to influence addictive behaviors, especially for alcoholism. SNPs ingenes for the catalytic enzymes for alcohol metabolism e.g. alcohol dehydrogenase $1 \mathrm{~B}$ or aldehyde dehydrogenase- 2 are sufficient to reduce the risk for alcoholism in some populations. Mutations in genes encoding the N-methyl-D-aspartate (NMDA) GluN2A subunit [39], mGlu5 receptors, or GABA receptors may lead to a higher risk of developing alcohol dependence. Individuals with variations in the genes for dopamine $\mathrm{D}_{2}$ receptors show younger onset and severity of drinking. SNPs in genes encoding for the $\mathrm{Y}_{2}$ receptor for neuropeptide
Y have been associated with alcohol dependence, alcohol withdrawal, comorbid alcohol use, and cocaine dependence. In comparison, SNPs in genes for neuropeptide $Y_{5}$ receptors are only associated with alcohol withdrawal in human studies [32]. Genome wide base associations studies (GWAS) identify chromosomal regions that are likely to contain allelic gene variants that contribute to human addiction vulnerability. These studies provide clues to the genetic bases of individual differences and provide tools for research in addictions to improve prevention and treatments of addiction [30]. To date 1,500 genes have been linked to an "addiction" phenotype in humans [40], some are related to the neuro adaptations following continued exposure; others are related to age of onset and patterns of use. Influence of genetic makeup on addiction appears additive; the more mutations an individual has, the greater his vulnerability to become addict $[32,41]$.

\section{Identifying the genes involved in addiction}

To establish a role for genes in addiction, approaches to identify the specific genes and its progress are applied. Two main molecular genetics approaches have been adopted to chase those genes that may be responsible for the genetic contribution to addiction: linkage and association. These approaches are not mutually exclusive, as the genetic regions identified by linkage may be refined subsequently by association and the causative gene difference(s) identified [42].

Generally for a linkage study, previously known as pedigree-based approach, DNA samples are needed from individuals in families that are multiply affected by addiction (multiplex families). Using approximately 300 markers, that is segments of DNA that may differ between individuals usually by size or sequence, the whole genetic complement can be screened for genes involved in the condition under study. As such, linkage can identify novel genes that are involved in conditions for which there has been no a priori reason to suspect any contribution. While this approach can be stated in such simple terms the actual analysis is much more complex, employing computer programs designed to identify a statistically significant coinheritance between a marker and the condition across the families.

Once linkage is detected, this implies that there is a gene, or genes, implicated in drug dependence in the proximity of the marker; hence efforts can then be made to identify which of the many possible genes are important. Essentially linkage is systematic, covering the human "genome", and has proved to be an excellent approach to identify genes that have large contributions to a condition. However, it is less useful where genetic contributions are relatively small and masked by complex gene-environment interactions. Thus far, linkage studies have not delivered on their early promise to identify the regions involved in drug dependence. However, as noted above, the linkage approach is ideally suited to those conditions that have genes of major effect, and the genes contributing to drug dependence may fall below the threshold for detection by this technique [42].

In many ways the second molecular genetics approach, using association studies, is more suited to identifying the genes that contribute to drug dependence, as they can pick up genes of relatively small effect, accounting for less than $2 \%$ of the variance. Association studies rely on a genetic change, occurring many generations before that alters an individual predisposition to a condition [43]. Gradually over the generations, through recombination of the genetic material that occur during the process of meiosis that produces eggs and sperm, the genetic variants that are further away from the genetic difference, conferring the vulnerability to drug dependence, become dissociated from it. Those markers that are very close to the genetic variation are very rarely dissociated from it and therefore the versions of these 
markers remain the same. Thus these, along with the vulnerability causing genetic variation, will be inherited as a block and as a result may occur at a different frequency in those with the condition when compared with the unaffected. These differences can be tested for significance simply by use of a $\left(\chi^{2}\right)$ test [44].

Association samples consist of seemingly unrelated individuals, although the approach is based on individuals being related many generations previously and rely on the increasing density of single nucleotide polymorphism (SNP) markers that can be assessed using "SNP chip" microarrays of increasing sophistication. The distribution of the variants of different genetic markers is compared between those with and without the condition of interest. If a statistically significant difference is identified, and this finding is replicated robustly, this suggests that the marker concerned is very close to the causal gene change increasing the vulnerability to the condition. Association studies are easier and cheaper to undertake than linkage approaches, although obtaining a suitable control sample often proves difficult. For example, are the best controls for smokers those who have never smoked ("supernormals") or those who are able to smoke but do not progress to dependence ("chippers")? [42].

These association approaches were termed genome-wide association (GWA) or whole genome association which can help elucidate chromosomal regions and genes that contain allelic variants that predispose to substance abuse without requiring family member participation. GWA gains power as densities of genomic markers increase. Association identifies smaller chromosomal regions than linkage-based approaches. GWA fosters pooling strategies that preserve confidentiality and reduce costs, such as the microarray-based approaches. GWA provides ample genomic controls that can minimize the chances of unintended ethnic mismatches between disease and control samples. The large numbers of comparisons that are key components of GWA do raise concerns, however [45].

By using this approach, it is possible to propose a systematic association study of the whole genome using DNA chips or arrays. These use short fragments of DNA, spotted onto a surface such as glass or plastic, which identify different variants of a marker by their ability to pair or match up with an individual's DNA. As such these chips, that are a few centimeters square, can examine up to a million markers in one reaction, thus permitting genome- wide scans. This approach can be made efficient and cost-effective by techniques that employ the pooling of DNA [46,47].

This is a systematic approach that can identify novel genes not predicted previously to be involved in addiction. However, the risk of false positives remains, compounded by the vast numbers of markers typed. In addition to the ubiquitous nature of false positives, true positives may be obscured further by gene-environment and gene-gene interactions. It is therefore vital that all associations reported should be treated with extreme caution until replicated robustly.

\section{Candidate polymorphisms for drug abuse based on dopamine theory}

Many factors make "Dopamine Theory" attractive for studying drug abuse vulnerability. First, virtually all addictive drugs are functional dopamine agonists; some direct, some indirect, some even trans-synaptic $[7,48,49]$. In fact, with the exception of the LSD and mescaline-like hallucinogens, functional dopamine agonism is the single pharmacological property that all addictive drugs share. Second, intracerebral micro-injections of dopamine agonists produce conditioned place preference and support volitional intracerebral self-administration [48]. Third, dopamine antagonists are negative reinforcers in animals and produce subjectively aversive effects in humans $[7,11]$. Fourth, when dopamine antagonists are administered to animals volitionally self-administering addictive drugs, a compensatory increase in addictive drug intake occurs, followed by extinction and cessation of the self-administration behavior [11]. Fifth, measures of real-time synaptic neurochemistry in the nucleus accumbens of test animals volitionally engaged in intravenous self-administration of addictive drugs (the real-time neurochemical sampling being achieved by in vivo brain microdialysis) show that: (a) following the first volitional self-administration of the test session, extracellular dopamine overflow in the nucleus accumbens displays a tonic increase of approximately 200\%; (b) thereafter, extracellular dopamine levels in the nucleus accumbens fluctuate phasically between approximately 200 and $100 \%$ over baseline, and (c) the low point of each phasic dip in extracellular nucleus accumbens dopamine accurately predicts the next volitional intake of addictive drug by the test animal [6]. Dopamine (DA) receptors has been the primary focus of genetic studies substance use disorders [50,51]. This system extends to a range of psychoactive substances, including opiates, cocaine, nicotine, and alcohol [19,52,53], through activation of the mesolimbic pathway, which is essential in drug reward and reinforcement [54]. A key mechanism in this pathway is dopamine activation of $\mathrm{DRD}_{2}$ receptors [19].

$\mathrm{DRD}_{2}$ gene on chromosome 11 ( $\left.\mathrm{q} 22-\mathrm{q} 23\right)$ has been extensively studied in relation to alcoholism, substance abuse, and nicotine dependence $[55,56]$. The human $\mathrm{DRD}_{2}$ is a G-protein coupled receptor located on postsynaptic dopaminergic neurons (OMIM\#126450) that is centrally involved in reward-mediating mesocorticolimbic pathways, it encodes two molecularly distinct isoforms with distinct functions. Signaling through $\mathrm{DRD}_{2}$ governs physiologic functions related to locomotion, hormone production, and drug abuse. $\mathrm{D}_{2}$ receptors are also known targets of antipsychotic drugs that are used to treat neuropsychiatric disorders such as schizophrenia [57].

Since the first reported association between TaqIA $\mathrm{DRD}_{2}$ minor $\left(\mathrm{A}_{1}\right)$ allele and severe alcoholism [58], large number of research studies has attempted to replicate this observation. In the first study, $A_{1}$ minor allele was associated with a seven-fold increase in susceptibility to alcohol abuse [59]. Whereas many studies have affirmed this significant association, others have not. This has generated controversy as to whether such an association actually exists [60]. At least eight independent meta-analyses of alcoholics and controls [43,61-67] have demonstrated this association to be robust. However, others stated that the effect size is small $[68,69]$. An earlier meta-analysis [70] did not find any significant association; however a re-analysis of that data did show a significant association $[71,72]$. The most frequently examined polymorphism linked to this gene is the Taq1A restriction fragment length polymorphism (RFLP) (dbSNP; rs1800497 cytogenetic location: 11q23.2 from NCBI; g.32806 C>T in GeneBank AF 050737.1), which has been associated with a reduction in $\mathrm{D}_{2}$ receptor density and consequently decreased dopaminergic activity, although this is not universally accepted [55] and in spite of being located outside the DNA region that encodes the $\mathrm{DRD}_{2}$ protein [71]. Other phenotypic difference that has been associated with subjects who carry the $\mathrm{DRD}_{2}$ " $\mathrm{A}_{1}$ " allele is diminished glucose metabolism in the brain [60]. The TaqI A RFLP lies within $10.5 \mathrm{~Kb}$ downstream of $\mathrm{DRD}_{2}$ and therefore, it falls within a different coding region than the $\mathrm{DRD}_{2}$ gene or within a regulatory region [55].

Within this downstream region, Neville et al have identified a novel kinase gene, named ankyrin repeat and kinase domain containing $1(\mathrm{ANKK} 1)$, which conatins a single serine/threonine kinase domain 
and is expressed at low levels in placenta and whole spinal cord RNA [55]. Consequently, TaqI A occurs in the $\mathrm{DRD}_{2}$ neighboring ankyrin repeat and kinase domain containing 1 (ANKK1) gene [29]. The TaqI A polymorphism may contribute to vulnerability to substance abuse and has been associated with polysubstance abuse [73], opioid dependence $[60,74]$, cocaine dependence [71], and psychostimulant polysubstance abuse [75]. Some studies have suggested that TaqI A is a risk factor for smoking behaviors [76-78], while other studies have not found these associations [56,79-81]. This SNP (C/T); the T allele is referred to as " $\mathrm{A}_{1}$ ", the $\mathrm{C}$ allele as " $\mathrm{A}_{2}$ "; individuals hetero or homozygous for the $\mathrm{T}$ allele are referred to as $\mathrm{A}_{1}+$, and individuals homozygous for the $\mathrm{C}$ allele are referred to as $\mathrm{A}_{1}-$. This polymorphism occurs in $\mathrm{DRD}_{2} / \mathrm{ANKK} 1$ exon 8 and results in a glu713-to-lys (E713K) non-conservative substitution; to date, this substitution has not been associated with a change in ANKK1 structural integrity, substrate-binding specificity, or function [82], and however, dopamine- related endophenotypes have been associated with the TaqI RFLP [83]. Moreover, ANKK1 and DRD2 genes have been shown to overlap, sharing halotypic blocks and furthermore it was shown that ANKK1 expression was significantly upregulated by the powerful dopamine receptor agonist apomorphine [84]. Although the precise relationship between TaqI A RFLP and DRD2 remains uncertain, there is convincing evidence that $\mathrm{A}_{1}+$ individuals have a 30 $40 \%$ reduction in $\mathrm{D} 2$ receptor density and availability in vivo, it must be noted, however, that there are data showed no significant differences in dopamine binding potential between $\mathrm{A}_{1}+$ and $\mathrm{A}_{1}$ - individuals [82].

Another variant associated with the $\mathrm{DRD}_{2}$ gene, called TaqI $\mathrm{B}$, located in the first intron near the junction with exon 2, also results in lower density of $\mathrm{DRD}_{2}$ receptors in the striatum. Individuals with this variant are more likely than those without it to have smoked and to have started smoking at an earlier age $[85,86]$ to be cocaine-dependent [63], and to abuse sychostimulants [75]. Most, but not all, studies of alcoholics and polysubstance abusers described higher frequencies of the $\mathrm{DRD}_{2}$ allele displaying $\mathrm{A}_{1}$ and $\mathrm{B}_{1}$ markers among substance abusers than control individuals. In fact, the same excess in $A_{1}$ and $B_{1}$ genotype frequencies has been found in polysubstance abusers and alcoholics. Therefore, increased frequencies of $\mathrm{DRD}_{2} \mathrm{~A}_{1}$ and $\mathrm{B}_{1}$ RFLPs might prove to be a function of severity of addictive process, rather than being associated with any one specific addiction alone [59].

However, Persico et al showed that the specific association between preferential psychostimulant use and the $\mathrm{DRD}_{2}$ TaqI $\mathrm{A}_{1}$ and $\mathrm{B}_{1}$ markers provides evidence that $\mathrm{DRD}_{2}$ allelic differences may play detectable roles in conferring vulnerability to specific patterns of drug use, rather than equally conferring general vulnerability towards all addictions [59]. The impact exerted by $\mathrm{DRD}_{2}$ gene variants might thus be described as a "modifying" influence, with more significance in specific subgroups of patients. The magnitude of this effect, however, is less profound than previously suggested by initial findings in alcoholics [58]. Conceivably, it could contribute most of the influences noted when mixed populations of polysubstance abusers are examined [59].

A large body of research suggests that there is a link between stressful life events and later health problems and could be a potential source of psychological problems [87]. However, it is unclear whether $\mathrm{DRD}_{2}$ polymorphisms may moderate the association between life events and consequent cardiovascular risks; a number of studies have analyzed association between $\mathrm{DRD}_{2}$ polymorphisms versus bipolar disorder and depressive symptoms, but no especial focus has been directed toward cardiovascular consequences. Additionally, a deletion variant (-141C Del) in the promoter region was associated with higher density of $\mathrm{DRD}_{2}$ receptors in the striatum [88] and with a higher likelihood of heroin abuse by inhalation, but not by injection.

\section{Candidate polymorphisms for drug abuse based on Serotonin transporter theory}

Serotonin (5-HT) with its mutual interactions with the dopamine network could potentially regulate the function of dopamine neurons, thus serotonin has a general inhibitory influence on the activity of dopamine neurons [89]. Furthermore, 5-HT has been shown to provide tonic and phasic control of glutamate neurotransmission within the limbic-corticostriatal reward pathway [90] and, as such, has become favorable target for novel strategies for development of pharmacotherapeutics for addiction [91]. 5-HT plays a large role in the neurochemical effects of several drugs of abuse, which may contribute to the development and maintenance of an addiction. Furthermore, $5-\mathrm{HT}$ is involved in modulating different aspects of impulsivity. Insight from preclinical models suggests that targeting specific 5-HT receptors may prove to be effective. There are at least 165 -HT receptor including 13 distinct G-protein coupled receptors coupled to various effector systems, and three ligand-gated ion channels [92,93]. Therefore there is a diverse landscape of available signaling cascades and mechanisms unparalleled in any other neurotransmitter system [51]. Central administration of exogenous serotonin increased and decreased blood pressure and heart rate, depending on the specific site of administration [94,95]. 5-HT transporter, depression and cardiovascular disease are a complex triad; depression is independently associated with a higher diastolic blood pressure and is significantly related to cardiovascular disease and morbidity. A recent study showed that the SS genotype of SERT (Serotonin Reuptake Transporter) is linked to major depressive disorder. Depression is also a risk factor for hypertension and myocardial infarction (MI). Similarly, clinical studies have demonstrated that hypertensive patients and MI patients are more likely to be depressed [96].

Appreciation for the potential influence of SERT on the cardiovascular system is growing with recent findings that possessing the $\boldsymbol{L} \boldsymbol{L}$ genotype, resulting in a higher expression and activity of SERT, sets individuals at a significantly higher risk for MI. To our knowledge, $\mathrm{MI}$ is the only published disease in which cardiovascular risk has been associated with presenting a particular gene type. A recent study of over 5000 individuals demonstrated a marked protection from MI in individuals who took SERT inhibitors/SSRIs and the extent of SERT inhibition among SSRIs correlates with the degree of reduction in MI risk. Thus, a lower SERT activity was associated with reduced risk of MI or coronary arterial vasospasm. Similarly, it was hypothesized that the use of SSRIs could also protect against MI by reducing platelet activation and concomitant vasospasm of coronary arteries [95,97]. SERT and the 5-HTRs are important sites of action for medications therapeutically effective in multiple psychiatric disorders (e.g. anxiety, depression, schizophrenia) and physiological disorders (e.g. migraine, irritable bowel syndrome) $[98,99]$. Growing evidence [100-104] also supports the prospects of therapeutic gains for serotonergic medications in alcohol and drug abuse disorders. Much of this research has focused on the utility for treatment of psychostimulant addicts because there are currently no medications for successfully maintaining recovery from psychostimulant addiction. In particular, a large body of pre-clinical evidence exists that describes an integral role for 5-HT modulation of the neurochemical and behavioural effects of cocaine [51].

Serotonergic neurotransmission is influenced by genetic factors; the serotonin transporter $(5-\mathrm{HTT})$ gene linked $5^{\prime}$ promoter region (5HTTLPR) variant and also other more recently described functional variants present likewise in the 5' region of SLC6A4 (i.e., rs25531, rs25532) plus an intronic variant (Stin2), and several exonic, rare coding region variants (SERT I425V, I425L and G56A) as well as 3' SLC6A4 
variants not yet as well-studied clinically. The serotonin transporter (5HTT) is encoded by the SLC6A4 or SERT gene and directs the reuptake of serotonin from the synapse into the presynaptic neuron [91]. The 5-HTTLPR occurs in short and long variants, depending on whether a 44-nucleotide sequence is deleted or not. The short variant reduces the transcriptional efficiency of the gene promoter, leading to decreased production of 5-HTT and hence a dysfunctional serotonin reuptake mechanism [29].

Human SLC6A4 (SERT) gene maps to chromosome 17q11.1-q12 and is composed of 14 exons spanning $40 \mathrm{~kb}$ (Figure 1). The sequence of the transcript predicts a protein comprised of 630 amino acids with 12 transmembrane domains. Alternative promoters, differential splicing involving exons $1 ; \mathrm{A}, \mathrm{B}$, and $\mathrm{C}$, and 3 '-untranslated-region (UTR) variability and other SNPs result in multiple mRNA species that regulate gene expression in humans and other species and in cultured cell lines. The 5HTTLPR, rs25531 and rs25532 in combination comprise multiple alleles, each with differing effects on gene expression. Ethnicity differences in the proportions of these variants exist across world populations, such that there is a 5 HTTLPR $40 \%$ difference in Caucasians vs. some Asian groups for the 5HTTLPR $\mathbf{S}$ allele and for rs 25531 a minor allele frequency of $9-15 \%$ in Caucasians and $24 \%$ in African- Americans. Several of the less common SLC6A4 coding SNPs are associated with behavioral phenotypes or disorders, including obsessive-compulsive disorder (SERT I425V is "OCD 1" in OMIM) and autism.

The LL genotype is supposed to display a two times higher transcriptional activity and a higher 5-HT uptake into the presynaptic neuron than SL and SS in the midbrain in healthy subjects $[105,106]$. LL homozygous serotonergic neurons have been shown to remove serotonin from the synaptic cleft more efficiently [105]. Lower levels of free serotonin have been associated with enhanced alcohol consumption. However, LL homozygous chronic alcoholic persons showed a low serotonin transporter binding compared to alcoholics carrying one or two short alleles [106]. So LL genotype confer a greater propensity toward alcohol-induced neurotoxic damage to the 5-HTT than the SS genotype [106]. Consequently, among alcoholics, those with the LL genotype might have reduced 5-HTT density and uptake. Due to this complex and in part confusing inter- action between alcoholism and the serotonergic and the dopaminergic system the present study tested whether the dopaminergic sensitivity in alcoholics is influenced by 5 -HTTLPR $[91,107]$.

The SLC6A4 intron 2 (STin2) polymorphic regions consists of three alleles: STin2.9; STin2.10 and STin2.12. This variable number of tandem repeats (VNTR) polymorphism yields enhanced expression proportionate to the number of repeat copies of the $16 / 17$ base pair element $(12>10>9)$, as determined in embryonic brain and stem cell preparations and in human JAR cells. The alleles of STin2 respond differentially to the transcription factors YB-1 and CTCF, which in turn, can be modulated by lithium chloride, an agent useful in the treatment of bipolar affective disorder [108]. Contrary to an extensive and constantly growing literature on the 5HTTLPR and STin 2 variants, clinical genetic research focusing on SLC6A4 3'UTR variants is sparse. SLC6A4 3'-UTR variants play important roles in mRNA translation,



\section{Human SLC6A4 (SEAT Gene) Organization, with Multiple Functional Variants}

\section{B. SERT Protein}

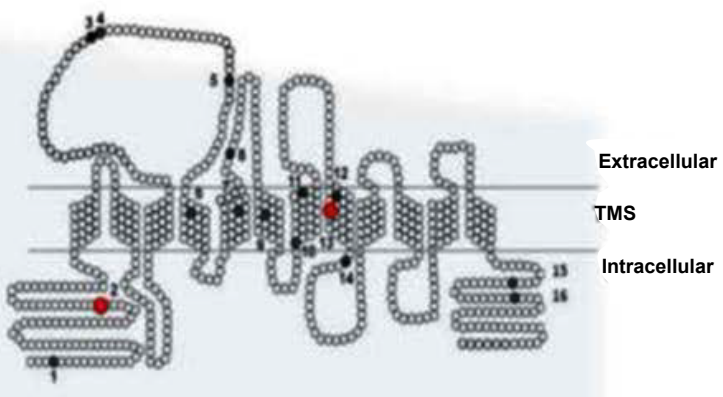

D. SERT Variant Combinations: Theoretical Additive Maximum Effects on \%-HT Transport

C. Functional Coding SERT SNPS
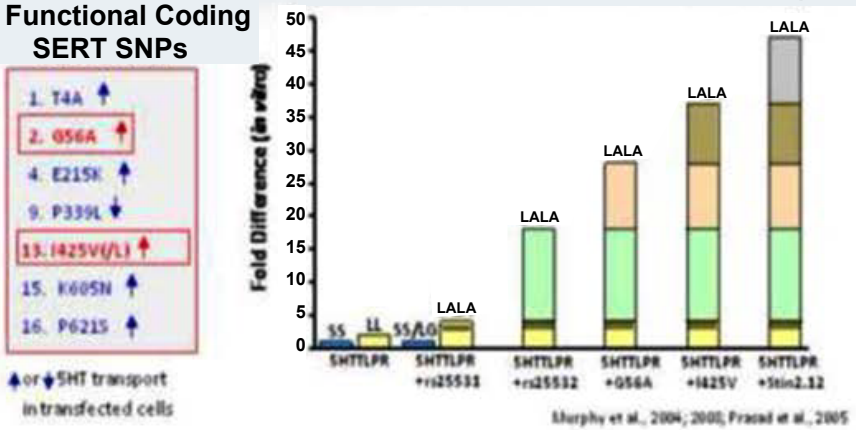

Figure 1: Human SLC6A4 (SERT gene) organization with multiple functional variants (Murphy and Moya, 2011). 
localization and stability. Thus, mutations in the 3'-UTR can affect the termination codon, poly adenylation (polyA) signals, the ratio of multiple polyA signal usage, as well as the secondary structure of the 3'-UTR mRNA, highlighting the multiple ways that polymorphisms in this region may cause a deregulated translational control and thereby disease. The SLC6A4 3'-UTR contains two poly A sites, located at 567 bp and $690 \mathrm{bp}$ downstream of the stop codon. These two sites are also present in mice, with a high degree of sequence similarity, suggesting that both sites have important, evolutionarily-conserved functions. The more distal of the polyA signals contains a common SNP (rs3813034) that alters the balance of the two polyA forms of SERT such that the $\mathrm{T}>\mathrm{G}$ allele of rs3813034 leads to an increase of the distal polyA signal [108].

\section{Comorbidity between drug abuse and ischemic heart diseases}

When two disorders or illnesses occur in the same person, simultaneously or sequentially, they are called comorbid. This also implies interactions between the illnesses that affect the course and prognosis of both. Comorbidity is a topic that stakeholders, patients, family members, health care professionals, and others frequently ask about. It is also a topic of insufficient information, and so it remains a research priority. Research on comorbidity offers avenues to better understand etiology, natural history, treatment utilization, and, ultimately, more effective treatment and prevention efforts for both disorders [3].

To help explain comorbidity, it is important to first recognize that drug abuse is a mental illness that commonly co-occur with other disorders; HIV, hepatitis C, cancer, cardiovascular disease . It is a complex brain disease characterized by compulsive, uncontrollable drug craving, seeking, and uses despite devastating consequences behaviors that stem from drug-induced changes in brain structure and function. These changes occur in some of the same brain areas that are disrupted in various other mental disorders, such as depression, anxiety, or schizophrenia. It is therefore not surprising that population surveys show a high rate of co-occurrence, or comorbidity, between drug addiction and other mental illnesses. Even though it is not always easy to prove a connection or causality, and certain mental disorders are not yet established risk factors for subsequent drug abuse and vice versa [109].

It is often difficult to disentangle the overlapping symptoms of drug addiction and other mental illnesses, making diagnosis and treatment complex. Correct diagnosis is critical to ensuring appropriate and effective treatment. Ignorance of or failure to treat a comorbid disorder can jeopardize a patient's chance of success. Enhanced understanding of the common genetic, environmental, and neural bases of these disorders and the dissemination of this information will lead to improved treatments for comorbidity and will diminish the social stigma that makes patients reluctant to seek the treatment they need [3].

In summary, the comorbid occurrence of substance use disorders with medical illness is common. The above examples underscore the need for physicians to be cognizant of and consider the role of substance use in patients presenting for medical treatment. A complete history inclusive of queries regarding drug and alcohol use should be a part of every examination. In patients known to have substance use disorders, potential etiology of medical illness should be considered. Effective treatment of substance use disorders will resolve some medical and mental illness while improving the course of other chronic diseases [109].
Providers should recognize that there is a range of overlapping symptoms that can be common both to substance misuse and to medical illness. For example, anorexia, weight loss, and fatigue may herald HIV disease or hepatitis but could also result from severe cocaine dependence. Fevers and night sweats may be symptoms of an infectious disease such as HIV or tuberculosis, but could also result from an infectious complication of drug abuse such as endocarditis or cellulitis. Another common clinical presentation with many possible etiologies is that of altered mental status. Altered mental status can be associated with many diseases: cardiovascular, cerebrovascular, hepatic, renal, pulmonary, endocrine, and infectious, as well as with dementia secondary to a substance use related illness (e.g., AIDS dementia complex) [109].

The intimate connection between the brain and the heart was enunciated by Claude Bernard over 150 years ago [110]. Neurocardiology has many dimensions; however, it may be conceptualized as divided into 3 major categories; (1) the heart's effects on the brain, (2) the brain's effects on the heart, (3) and concomitant neurocardiac affection. An increasing body of evidences shows that the nervous system has the capacity to injure the heart. This area of research is indeed important and represents an example of a much more wide-spread and conceptually fascinating area of neurovisceral damage in general [4].

In recent years, increasing evidences suggest that central role of genetic and epigenetic factors could be involved in disease comorbidity. Genes and Gene expression products are essential for the development and function of the brain and heart [111]. The single nucleotide polymorphisms (SNPs) and changes in miRNA expression profiles are associated with an increased risk for developing neurodegenerative disorders as well as heart failure but there are less known about how these factors may influence the co-occurrence of drug abuse disorder and cardiovascular risks [3].

\section{Common factors overlapping genetic vulnerabilities}

A particularly active area of comorbidity research involves the search for genes that might predispose individuals to develop both addiction and cardiovascular illnesses, or to have a greater risk of a second disorder occurring after the first appears. It is estimated that $40-60 \%$ of an individual's vulnerability to addiction is attributable to genetics; most of this vulnerability arises from complex interactions among multiple genes and from genetic interactions with environmental influences. In some instances, a gene product (protein) may directly affect person's response to a drug or duration of drug persistence within the body. Moreover genes can act indirectly through the person's behavior towards stress which could influence the development of both drug use disorders and other illnesses. Several regions of the human genome have been linked to increased risk of both, including associations with greater vulnerability to drug dependence and cardiac disorders $[1,15,24]$.

Dopamine (DA) neurotransmission through $\mathrm{DRD}_{2}$ is thought to be a primary mechanism in the regulation of reward processing and reinforcement, cognitive and effects of drugs of abuse [112]. Several studies have implicated a role for the products of dopamine receptor gene variants in mediating the behavioral and neurochemical properties of opiates such as heroin. It has also been suggested that the endogenous dopamine system may also contribute to the development of dependence on other drugs of abuse such as alcohol, cannabis, cocaine and amphetamines [113]. A deficient $\mathrm{DRD}_{2}$ formation or action may contribute to hypertension via an increase of the catecholamine release [114] and also has significant effects in responses to stressors and salient aversive stimuli [112]. There is a link between stressful life 
events and later health problems. Major or cumulative life events have also demonstrated a relationship with health-risk behaviors, such as smoking, alcohol dependence and polysubstance abuse [87].

A similar, if not identical, cardiac lesion can be produced with various models of stress. This concept was applied to the heart when Selye published his monograph "The chemical prevention of cardiac necrosis" in 1958. This so-called stress could be of multiple types such as restraint, surgery, bacteremia, vagotomy, and toxins. He believed that the first mediator in the translation of these widely disparate stimuli into a stereotyped cardiac lesion was the hypothalamus and that it, by its control over the autonomic nervous system, caused the release of certain agents that were toxic to the myocardial cell. Since Selye's original work, similar experiments have been repeated in many different types of laboratory animals with comparable results [4]. Nervous system stimulation produces cardiac lesions that are histologically indistinguishable from those described for stress and catecholamineinduced cardiac damage. It has been known for a long time that stimulation of the hypothalamus can lead to autonomic cardiovascular disturbances and many years ago lesions in the heart and gastrointestinal tract have been produced with hypothalamic stimulation. It has been clearly demonstrated that stimulation of the lateral hypothalamus produces hypertension and/or electrocardiographic (ECG) changes reminiscent of those seen in patients with central nervous system damage of various types. Furthermore, this effect on the blood pressure and ECG can be completely prevented by C2 spinal section and stellate ganglionectomy, but not by vagotomy, which suggests that the mechanism of ECG changes is sympathetic rather than parasympathetic or humoral [4].

A genetic contribution of human serotonin (5-HT) transporter (SERT) gene (SLC6A4) variants to temperament and behavioral traits including anxiety, excess stress responsiveness and drug abuse/ dependence has been established in human. Other disorder reported to show associations with (SLC6A4) genotypes or alleles include myocardial infarction (5-HTTLPR $S$ allele protective in delaying age of onset) and the $\boldsymbol{L} \boldsymbol{L}$ genotype associated with greater risk for myocardial infarction in additional studies $(\mathrm{OR}=1.4, N>600)$ [115118]. Mechanisms involved to explain the cardiovascular associations include excess 5-HT accumulation in platelets related to greater SERT expression due to the $\mathrm{L}$ allele and hence enhanced release of 5-HT, as well as direct effects of 5-HT on vascular proliferation [95,115].

\section{References}

1. Kuhar MJ, Joyce A, Dominguez G (2001) Genes in drug abuse. Drug Alcohol Depend 62: 157-162.

2. Buscemi L, Onori N, Turchi C, Solito G, Tagliabracci A (2009) Genetic susceptibility for addiction: Searching of risk loci for the widespread drugs of abuse. Forensic Science International: Genetics Supplement Series 2: 487488

3. NIDA (2008) Comorbidity: Addiction and Other Mental Illnesses. In D. Nora \& M. D. Volkow (Eds.), Research report. Bethesda, Maryland: National Institute on Drug of Abuse 1-12.

4. Samuels MA (2007) The brain-heart connection. Circulation 116: 77-84.

5. Hébert SS (2009) Putative Role of MicroRNA-Regulated Pathways in Comorbid Neurological and Cardiovascular Disorders. Cardiovasc Psychiatry Neurol 2009: 849519.

6. Gardner EL (2011) Addiction and brain reward and antireward pathways. Adv Psychosom Med 30: 22-60.

7. Gardner EL (2005) Brain reward mechanisms. In 4 (Ed.), Substance Abuse. A Comprehensive Text book, Lippincott Williams \& Wilkins 48-97.

8. Robinson TE, Berridge KC (2003) Addiction. Annu Rev Psychol 54: 25-53.

9. Schramm-Sapyta NL, Walker QD, Caster JM, Levin ED, Kuhn CM (2009) Are adolescents more vulnerable to drug addiction than adults? Evidence from animal models. Psychopharmacology (Berl) 206: 1-21.

10. Karch SB (2008) Addiction and the medical complications of drug abuse. Boca Raton; London: CRC Press.

11. O'Brien CP, Gardner EL (2005) Critical assessment of how to study addiction and its treatment: human and non-human animal models. Pharmacol Ther 108 18-58.

12. Darke S, Ross J, Zador D, Sunjic S (2000) Heroin-related deaths in New South Wales, Australia, 1992-1996. Drug Alcohol Depend 60: 141-150.

13. Dackis C, O'Brien C (2005) Neurobiology of addiction: treatment and public policy ramifications. Nat Neurosci 8: 1431-1436.

14. Balster RL (1991) Drug abuse potential evaluation in animals. $\mathrm{Br} \mathrm{J}$ Addict 86 1549-1558.

15. Vanyukov MM, Tarter RE (2000) Genetic studies of substance abuse. Drug Alcohol Depend 59: 101-123.

16. Leshner Al (1997) Addiction is a brain disease, and it matters. Science 278: 45-47.

17. Helzer JE, Burnam A, McEvoy LT (1991) Alcohol abuse and dependence. Psychiatric disorders in America.The Epidemiologic Catchment Area Study. New York: The Free Press 81-115.

18. Kandel DB, Yamaguchi K, Chen K (1992) Stages of progression in drug involvement from adolescence to adulthood: further evidence for the gateway theory. J Stud Alcohol 53: 447-457.

19. Koob GF, Le Moal M (2001) Drug addiction, dysregulation of reward, and allostasis. Neuropsychopharmacology 24: 97-129.

20. Merikangas KR, Stolar M, Stevens DE, Goulet J, Preisig MA, et al. (1998) Familial transmission of substance use disorders. Arch Gen Psychiatry 55: 973-979.

21. Tsuang MT, Lyons MJ, Eisen SA, Goldberg J, True W, et al. (1996) Genetic influences on DSM-III-R drug abuse and dependence: a study of 3,372 twin pairs. Am J Med Genet 67: 473-477.

22. Bierut LJ, Dinwiddie SH, Begleiter H, Crowe RR, Hesselbrock V, et al. (1998) Familial transmission of substance dependence: alcohol, marijuana, cocaine, and habitual smoking: a report from the Collaborative Study on the Genetics of Alcoholism. Arch Gen Psychiatry 55: 982-988.

23. Lessov CN, Swan GE, Ring HZ, Khroyan TV, Lerman C (2004) Genetics and drug use as a complex phenotype. Subst Use Misuse 39: 1515-1569.

24. Uhl GR, Liu QR, Naiman D (2002) Substance abuse vulnerability loci: converging genome scanning data. Trends Genet 18: 420-425.

25. Kreek MJ, Nielsen DA, LaForge KS (2004) Genes associated with addiction alcoholism, opiate, and cocaine addiction. Neuromolecular Med 5: 85-108.

26. Tsuang MT, Lyons MJ, Meyer JM, Doyle T, Eisen SA, et al. (1998) Cooccurrence of abuse of different drugs in men: the role of drug-specific and shared vulnerabilities. Arch Gen Psychiatry 55: 967-972.

27. Kendler KS, Karkowski LM, Neale MC, Prescott CA (2000) Illicit psychoactive substance use, heavy use, abuse, and dependence in a US population-based sample of male twins. Arch Gen Psychiatry 57: 261-269.

28. Uhl GR, Drgon T, Johnson C, Fatusin OO, Liu QR, et al. (2008) "Higher order" addiction molecular genetics: convergent data from genome-wide association in humans and mice. Biochem Pharmacol 75: 98-111.

29. Mroziewicz M, Tyndale RF (2010) Pharmacogenetics: a tool for identifying genetic factors in drug dependence and response to treatment. Addict Sci Clin Pract 5: 17-29.

30. Uhl GR (2004) Molecular genetic underpinnings of human substance abuse vulnerability: likely contributions to understanding addiction as a mnemonic process. Neuropharmacology 47: 140-147.

31. Ho MK, Goldman D, Heinz A, Kaprio J, Kreek MJ, et al. (2010) Breaking barriers in the genomics and pharmacogenetics of drug addiction. Clin Pharmacol Ther 88: 779-791.

32. Duncan JR (2012) Current perspectives on the neurobiology of drug addiction: a focus on genetics and factors regulating gene expression. ISRN Neurol 2012 : 972607.

33. Urbanoski KA, Kelly JF (2012) Understanding genetic risk for substance use and addiction: a guide for non-geneticists. Clin Psychol Rev 32: 60-70. 
34. Karkowski LM, Prescott CA, Kendler KS (2000) Multivariate assessment of factors influencing illicit substance use in twins from female-female pairs. Am J Med Genet 96: 665-670.

35. True WR, Heath AC, Scherrer JF, Xian H, Lin N, et al. (1999) Interrelationship of genetic and environmental influences on conduct disorder and alcohol and marijuana dependence symptoms. Am J Med Genet 88: 391-397.

36. Uhl GR, Elmer GI, Labuda MC, Pickens RW (1995) Genetic influences in drug abuse Psychopharmacology: the fourth generation of progress.New York: Raven Press 1793-2783.

37. Glantz MD (1992)Adevelopmantal psychopathology model of drug abuse vulnerability Vulnerability to drug abuse. Washington: American Psychological Association 389-418.

38. Tarter RE, Mezzich AC (1992) Ontogeny of substance abuse: perspectives and findings Vulnerability to drug abuse. Washington: American Psychological Association 149-178.

39. Schumann G, Johann M, Frank J, Preuss U, Dahmen N, et al. (2008) Systematic analysis of glutamatergic neurotransmission genes in alcohol dependence and adolescent risky drinking behavior. Arch Gen Psychiatry 65: 826-838.

40. Li CY, Mao X, Wei L (2008) Genes and (common) pathways underlying drug addiction. PLoS Comput Biol 4: e2.

41. Dick DM, Foroud T (2003) Candidate genes for alcohol dependence: a review of genetic evidence from human studies. Alcohol Clin Exp Res 27: 868-879.

42. Ball D (2007) Addiction science and its genetics. Addiction 103: 360-367.

43. Noble EP (1998) The D2 dopamine receptor gene: a review of association studies in alcoholism and phenotypes. Alcohol 16: 33-45.

44. Sham P, McGuffin P (2002) Linkage and association. In P. McGuffin, M. Owen \& I IGottesman (Eds.), Psychiatric Genetics and Genomics. Oxford: Oxford University Press. 55-73.

45. Schena M, Heller RA, Theriault TP, Konrad K, Lachenmeier E, et al. (1998) Microarrays: biotechnology's discovery platform for functional genomics. Trends Biotechnol 16: 301-306.

46. Schmith VD, Campbell DA, Sehgal S, Anderson WH, Burns DK, et al. (2003) Pharmacogenetics and disease genetics of complex diseases. Cell Mol Life Sci 60: 1636-1646.

47. Uhl GR, Liu QR, Drgon T, Johnson C, Walther D, et al. (2007) Molecula genetics of nicotine dependence and abstinence: whole genome association using 520,000 SNPs. BMC Genet 8: 10.

48. Gardner EL, David J (1999)The neurobiology of chemical addiction Getting Hooked. Rationality and the Addictions. Cambridge: University Press 93-136.

49. Wise RA, Gardner EL (2002) Functional anatomy of substance-related disorders Biological Psychiatry. New York, Wiley 509-522.

50. Vocci FJ, Acri J, Elkashef A (2005) Medication development for addictive disorders: the state of the science. Am J Psychiatry 162: 1432-1440.

51. Bubar MJ, Cunningham KA (2008) Prospects for serotonin 5-HT2R pharmacotherapy in psychostimulant abuse. Prog Brain Res 172: 319-346.

52. Munafò M, Rigotti N, Lancaster T, Stead L, Murphy M (2001) Interventions for smoking cessation in hospitalised patients: a systematic review. Thorax 56 656-663

53. Lingford-Hughes A, Nutt D (2003) Neurobiology of addiction and implications for treatment. Br J Psychiatry 182: 97-100.

54. Di Chiara G, Bassareo V (2007) Reward system and addiction: what dopamine does and doesn't do. Curr Opin Pharmacol 7: 69-76.

55. Neville MJ, Johnstone EC, Walton RT (2004) Identification and characterization of ANKK1: a novel kinase gene closely linked to DRD2 on chromosome band 11q23.1. Hum Mutat 23: 540-545

56. Munafò MR, Timpson NJ, David SP, Ebrahim S, Lawlor DA (2009) Association of the DRD2 gene Taq1A polymorphism and smoking behavior: a meta-analysis and new data. Nicotine Tob Res 11: 64-76.

57. Usiello A, Baik JH, Rougé-Pont F, Picetti R, Dierich A, et al. (2000) Distinct functions of the two isoforms of dopamine D2 receptors. Nature 408: 199-203.

58. Blum K, Noble EP, Sheridan PJ, Montgomery A, Ritchie T, et al. (1990) Allelic association of human dopamine D2 receptor gene in alcoholism. JAMA 263: 2055-2060.
59. Persico AM, Smith SS, Uhl GR (1993) D2 receptor gene variants and substance abuse liability. Seminars in Neuroscience 5: 377-382.

60. Noble EP (2003) D2 dopamine receptor gene in psychiatric and neurologic disorders and its phenotypes. Am J Med Genet B Neuropsychiatr Genet 116B: 103-125.

61. Cloninger CR (1991) D2 dopamine receptor gene is associated but not linked with alcoholism. JAMA 266: 1833-1834

62. Pato CN, Macciardi F, Pato MT, Verga M, Kennedy JL (1993) Review of the putative association of dopamine D2 receptor and alcoholism: a meta-analysis. Am J Med Genet 48: 78-82.

63. Uhl G, Blum K, Noble E, Smith S (1993) Substance abuse vulnerability and D2 receptor genes. Trends Neurosci 16: 83-88.

64. Gorwood P, Ades J, Feingold J (1994) Are genes coding for dopamine receptors implicated in alcoholism? European Psychiatry 9: 63-69.

65. Blum K, Sheridan PJ, Wood RC, Braverman ER, Chen TJ, et al. (1995) Dopamine D2 receptor gene variants: association and linkage studies in impulsive-addictive-compulsive behaviour. Pharmacogenetics 5: 121-141.

66. Neiswanger K, Hill SY, Kaplan BB (1995) Association and linkage studies of the TAQI A1 allele at the dopamine D2 receptor gene in samples of female and male alcoholics. Am J Med Genet 60: 267-271.

67. Gurling H, Cook CC (1999) The genetic predisposition to alcohol dependence. Curr Opin Psychiatry 12: 269-275.

68. Munafò MR, Matheson IJ, Flint J (2007) Association of the DRD2 gene Taq1A polymorphism and alcoholism: a meta-analysis of case-control studies and evidence of publication bias. Mol Psychiatry 12: 454-461.

69. Smith L, Watson M, Gates S, Ball D, Foxcroft D (2008) Meta-analysis of the association of the Taq1A polymorphism with the risk of alcohol dependency: a HuGE gene-disease association review. Am J Epidemiol 167: 125-138.

70. Gelernter J, Goldman D, Risch N (1993) The A1 allele at the D2 dopamine receptor gene and alcoholism. A reappraisal. JAMA 269: 1673-1677.

71. Noble EP, Blum K, Khalsa ME, Ritchie T, Montgomery A, et al. (1993) Allelic association of the D2 dopamine receptor gene with cocaine dependence. Drug Alcohol Depend 33: 271-285.

72. Noble EP, Blum K (1993) Alcoholism and the D2 dopamine receptor gene. JAMA 270: 1547-1548

73. O'Hara BF, Smith SS, Bird G, Persico AM, Suarez BK, et al. (1993) Dopamine D2 receptor RFLPs, haplotypes and their association with substance use in black and Caucasian research volunteers. Hum Hered 43: 209-218.

74. Lawford BR, Young RM, Noble EP, Sargent J, Rowell J, et al. (2000) The D(2) dopamine receptor $A(1)$ allele and opioid dependence: association with heroin use and response to methadone treatment. Am J Med Genet 96: 592-598.

75. Persico AM, Bird G, Gabbay FH, Uhl GR (1996) D2 dopamine recepto gene Taql $A 1$ and $B 1$ restriction fragment length polymorphisms: enhanced frequencies in psychostimulant-preferring polysubstance abusers. Biol Psychiatry 40: 776-784.

76. Comings DE, Ferry L, Bradshaw-Robinson S, Burchette R, Chiu C, et al. (1996) The dopamine D2 receptor (DRD2) gene: a genetic risk factor in smoking Pharmacogenetics 6: 73-79.

77. Erblich J, Lerman C, Self DW, Diaz GA, Bovbjerg DH (2005) Effects of dopamine D2 receptor (DRD2) and transporter (SLC6A3) polymorphisms on smoking cue-induced cigarette craving among African-American smokers. Mol Psychiatry 10: 407-414.

78. Huang W, Payne TJ, Ma JZ, Beuten J, Dupont RT, et al. (2009) Significant association of ANKK1 and detection of a functional polymorphism with nicotine dependence in an African-American sample. Neuropsychopharmacology 34: 319-330.

79. Munafò M, Clark T, Johnstone E, Murphy M, Walton R (2004) The genetic basis for smoking behavior: a systematic review and meta-analysis. Nicotine Tob Res 6. 583-597.

80. Johnstone EC, Yudkin P, Griffiths SE, Fuller A, Murphy M, et al. (2004) The dopamine D2 receptor C32806T polymorphism (DRD2 Taq1A RFLP) exhibits no association with smoking behaviour in a healthy UK population. Addict Biol 9: 221-226.

81. Berlin I, Covey LS, Jiang H, Hamer D (2005) Lack of effect of D2 dopamine 
receptor Taql A polymorphism on smoking cessation. Nicotine Tob Res 7: 725728.

82. Cameron JD, Riou MË, Tesson F, Goldfield GS, Rabasa-Lhoret R, et al. (2013) The TaqIA RFLP is associated with attenuated intervention-induced body weight loss and increased carbohydrate intake in post-menopausal obese women. Appetite 60: 111-116.

83. Rodríguez-Jiménez R, Avila C, Ponce G, Ibáñez MI, Rubio G, et al. (2006) The TaqIA polymorphism linked to the DRD2 gene is related to lower attention and less inhibitory control in alcoholic patients. Eur Psychiatry 21: 66-69.

84. Hoenicka J, Quiñones-Lombraña A, España-Serrano L, Alvira-Botero X, Kreme $\mathrm{L}$, et al. (2010) The ANKK1 gene associated with addictions is expressed in astroglial cells and upregulated by apomorphine. Biol Psychiatry 67: 3-11.

85. Spitz MR, Shi H, Yang F, Hudmon KS, Jiang H, et al. (1998) Case-control study of the D2 dopamine receptor gene and smoking status in lung cancer patients. J Natl Cancer Inst 90: 358-363.

86. Wu X, Hudmon KS, Detry MA, Chamberlain RM, Spitz MR (2000) D2 dopamine receptor gene polymorphisms among African-Americans and MexicanAmericans: a lung cancer case-control study. Cancer Epidemiol Biomarkers Prev 9: 1021-1026.

87. Elovainio M, Jokela M, Kivimäki M, Pulkki-Råback L, Lehtimäki T, et al. (2007) Genetic variants in the DRD2 gene moderate the relationship between stressful life events and depressive symptoms in adults: cardiovascular risk in young Finns study. Psychosom Med 69: 391-395.

88. Arinami T, Gao M, Hamaguchi H, Toru M (1997) A functional polymorphism in the promoter region of the dopamine D2 receptor gene is associated with schizophrenia. Hum Mol Genet 6: 577-582.

89. Skowronek MH, Laucht M, Hohm E, Becker K, Schmidt MH (2006) Interaction between the dopamine D4 receptor and the serotonin transporter promoter polymorphisms in alcohol and tobacco use among 15-year-olds. Neurogenetics 7: 239-246.

90. Alex KD, Pehek EA (2007) Pharmacologic mechanisms of serotonergic regulation of dopamine neurotransmission. Pharmacol Ther 113: 296-320.

91. Budde H, Sander T, Wernicke C, Müller A, Gallinat J, et al. (2010) Serotonin transporter promoter polymorphism and dopaminergic sensitivity in alcoholics. J Neural Transm 117: 133-138.

92. Hoyer D, Hannon JP, Martin GR (2002) Molecular, pharmacological and functional diversity of 5-HT receptors. Pharmacol Biochem Behav 71: 533-554.

93. Green AR (2006) Neuropharmacology of 5-hydroxytryptamine. Br J Pharmaco 147: S145-S152.

94. Cooper JR, Bloom FE, Roth RH (2003) The biochemical basis of neuropharmacology (8th ed.) Oxford: Oxford University Press.

95. Ni W, Watts SW (2006) 5-hydroxytryptamine in the cardiovascular system: focus on the serotonin transporter (SERT). Clin Exp Pharmacol Physiol 33: $575-583$

96. Way BM, Taylor SE (2011) A polymorphism in the serotonin transporter gene moderates cardiovascular reactivity to psychosocial stress. Psychosom Med 73: $310-317$

97. Brummett BH, Siegler IC, Ashley-Koch A, Williams RB (2011) Effects of 5HTTLPR on cardiovascular response to an emotional stressor. Psychosom Med 73: 318-322.

98. Naughton M, Mulrooney JB, Leonard BE (2000) A review of the role of serotonin receptors in psychiatric disorders. Hum Psychopharmacol 15: 397-415.

99. Jones BJ, Blackburn TP (2002) The medical benefit of 5-HT research PharmacolBiochemBehav 71: 555-568.

100. Rothman RB, Blough BE, Baumann MH (2006) Dual dopamine-5-HT releasers: potential treatment agents for cocaine addiction. Trends Pharmaco Sci 27: 612-618.

101. El-Mallakh RS, Abraham HD (2007) MDMA (Ecstasy). Ann Clin Psychiatry 19: 45-52.

102. Hughes JR, Stead LF, Lancaster T (2007) Antidepressants for smoking cessation. Cochrane Database Syst Rev CD000031.

103. Levin ED, Rezvani AH (2007) Nicotinic interactions with antipsychotic drugs, models of schizophrenia and impacts on cognitive function. Biochem Pharmacol 74: 1182-1191.
04. Lesch KP, Bengel D, Heils A, Sabol SZ, Greenberg BD, et al. (1996) Association of anxiety-related traits with a polymorphism in the serotonin transporter gene regulatory region. Science 274: 1527-1531.

105. Reimold M, Smolka MN, Schumann G, Zimmer A, Wrase J, et al. (2007) Midbrain serotonin transporter binding potential measured with [11C]DASB is affected by serotonin transporter genotype. J Neural Transm 114: 635-639.

106. Heinz A, Jones DW, Mazzanti C, Goldman D, Ragan P, et al. (2000) A relationship between serotonin transporter genotype and in vivo protein expression and alcohol neurotoxicity. Biol Psychiatry 47: 643-649.

107.Schmidt LG, Smolka M (2001) Relapse prevention in alcoholics by cigarette smoking? Involvement of nicotinic-dopaminergic mechanisms. Alcohol 24 111-115.

108. Ali FR, Vasiliou SA, Haddley K, Paredes UM, Roberts JC, et al. (2010) Combinatorial interaction between two human serotonin transporter gene variable number tandem repeats and their regulation by CTCF. J Neurochem 112: $296-306$

109.Draper JC, McCance-Katz EF (2005) Medical illness and comorbidities in drug users: implications for addiction pharmacotherapy treatment. Subst Use Misuse 40: 1899-1921.

110. Thayer JF, Ahs F, Fredrikson M, Sollers JJ 3rd, Wager TD (2012) A metaanalysis of heart rate variability and neuroimaging studies: implications for heart rate variability as a marker of stress and health. Neurosci Biobehav Rev 36: 747-756.

111. Hasin D, Kilcoyne B (2012) Comorbidity of psychiatric and substance use disorders in the United States: current issues and findings from the NESARC. Curr Opin Psychiatry 25: 165-171.

112. Peciña M, Mickey BJ, Love T, Wang H, Langenecker SA, et al. (2013) DRD2 polymorphisms modulate reward and emotion processing, dopamine neurotransmission and openness to experience. Cortex 49: 877-890.

113. Al-Eitan LN, Jaradat SA, Hulse GK, Tay GK (2012) Custom genotyping for substance addiction susceptibility genes in Jordanians of Arab descent. BMC Res Notes 5: 497.

114. Rosmond R, Rankinen T, Chagnon M, Pérusse L, Chagnon YC, et al. (2001) Polymorphism in exon 6 of the dopamine $D(2)$ receptor gene (DRD2) is associated with elevated blood pressure and personality disorders in men. $J$ Hum Hypertens 15: 553-558.

115. Ulrich S, Hersberger M, Fischler M, Nussbaumer-Ochsner Y, Treder U, et al (2010) Genetic polymorphisms of the serotonin transporter, but not the $2 a$ receptor or nitric oxide synthetase, are associated with pulmonary hypertension in chronic obstructive pulmonary disease. Respiration 79: 288-295.

116. Li T, Liu X, Zhao J, Hu X, Ball DM, et al. (2002) Allelic association analysis of the dopamine D2, D3, 5-HT2A, and $\mathrm{GABA}(\mathrm{A})$ gamma2 receptors and serotonin transporter genes with heroin abuse in Chinese subjects. Am J Med Genet 114: 329-335.

117. Murphy DL, Li Q, Engel S, Wichems C, Andrews A, et al. (2001) Genetic perspectives on the serotonin transporter. Brain Res Bull 56: 487-494.

118. Obot IS, Poznyak V, Monteiro M (2004) From basic research to public health policy: WHO report on the neuroscience of substance dependence. Addict Behav 29: 1497-1502. 